\title{
Quality of life and occupational performance of children with cancer in the era of the COVID-19 pandemic in terms of rehabilitation
}

\author{
Gözde Önal' ${ }^{1} \cdot$ Güleser Güney ${ }^{2} \cdot$ Meral Huri $^{3}$ \\ Accepted: 21 April 2021 / Published online: 3 May 2021 \\ (c) The Author(s), under exclusive licence to Springer Nature Switzerland AG 2021
}

\begin{abstract}
Purpose This study was designed to determine the changes in the quality of life (QOL) and occupational performance of children with cancer and to examine their rehabilitation needs during the pandemic period in Turkey.

Methods 60 children with cancer and their families participated in the study. The first and second assessments were carried out in April and September 2020, respectively. The pediatric quality of life inventory parent proxy-report was used to evaluate the QOL, and the Canadian occupational performance measurement was used to evaluate children's occupational performance and satisfaction. A qualitative interview was planned to determine the impact of the pandemic on children with cancer alongside their families and therefore determining the rehabilitation needs of the children.

Results While there is no statistically significant change in the pain-related conditions of the children in the first six months of the pandemic $(p>0.05)$, procedural and treatment anxieties of the children increased during the treatment. Their QOL including cognitive state, perceived physical appearance and communication skills also showed a statistically significant decrease $(p<0.05)$. Both the occupational performance and satisfaction scores decreased significantly, covering the prepandemic and pandemic era $(p<0.01)$. In the qualitative interview parents expressed their children's need for physical, psychological and social participation support. Also, they emphasized the need for time management.

Conclusions During the COVID-19 pandemic, the QOL and occupational performance level of children with cancer decreased significantly. Holistic rehabilitation approaches complying with pandemic conditions are likely to benefit these children.
\end{abstract}

Keywords Pandemic $\cdot$ COVID-19 $\cdot$ Children with cancer $\cdot$ Rehabilitation needs $\cdot$ Quality of life $\cdot$ Occupational performance

\section{Introduction}

In March 2020, the World Health Organization (WHO) declared the COVID-19 (Coronavirus Disease 2019) outbreak a global pandemic $[1,2]$. Threatening human life, COVID-19 has affected the universe, and beyond its astonishing impact on the health and survival of numerous people, it is predicted to continue to affect millions of people, given

Gözde Önal

gozdeonal0@gmail.com

1 Therapy and Rehabilitation Department, Hacı Bektaş Veli University, Nevşehir, Türkiye

2 Therapy and Rehabilitation Department, Kütahya Health Sciences University, Kütahya, Türkiye

3 Occupational Therapy Department, Hacettepe University, Ankara, Turkey the need to rebuild life in response to an evolving pandemic [3].

As researchers put a lot of effort into an effective antiviral and vaccine against COVID-19, the psychological impact of the disease is largely neglected. These new and constantly revised restrictions to daily living and social activities along with the risk of losing a job can have serious mental health consequences $[4,5]$. The COVID-19 quarantine has been imposed to combat an uncertain and persistent threat, which can contribute to intensify anxiety and increase individuals' fear of the unknown, reducing individuals' QOL [6, 7]. Recent research has shown that the fear created by the COVID-19 pandemic can become chronic and burdensome, anxiety, social media exposure, among other factors may be predictors of higher levels of this fear [8].

The impact of COVID-19 on QOL can be more devastating for children [9]. Childhood, a sensitive period for social 
development, includes many biopsychosocial changes, including gaining independence from parents, and coping with daily life and school challenges $[10,11]$. The healthrelated QOL of children is negatively affected by the rapid implementation of social distancing measures necessary to prevent the spread of the pandemic, and children's feelings of loneliness increase [12-14].

The challenges and consequences of COVID-19 therefore have a tremendous impact on QOL [9]. Recent research in various parts of the world has reported that the psychological well-being and general QOL of children have worsened compared to the time before the pandemic [15-18]. In addition, Sieberer et al. [9] stated that the QOL of children and adolescents decreased during the pandemic period; and the QOL of children with chronic illnesses like childhood cancer have shown that the decrease is more than their peers.

There is a growing need for cancer research now in particular, as the immunosuppressive effect of cancer and its related treatments increases the risk of different infectious diseases among patients including COVID-19 [19, 20]. Analysis of 38 eligible studies involving 7094 patients indicates that patients with cancer or cancer survivors are at an elevated risk for infection with the COVID-19 and are associated with severe cases and risk of death [21]. From a QOL perspective, the necessity to take higher-level measures than the normal population creates an extra burden for individuals with cancer [22, 23]. Ciążyńska et al. [22] stated that under the COVID-19 lockdown, most cancer patients feel fatigue due to stress and uncertainty associated with cancer treatments and COVID-19 infection, while the COVID-19 pandemic reduces their sense of security and significantly affects their daily functioning. Younger et al. [23] reported that high COVID-19 worry is significantly associated with high insomnia and low emotional functioning of individuals with cancer.

Children with weakened immune systems due to cancer have an increased risk of suffering from the devastating effects of the virus [24]. Children who come into contact with COVID-19 while suffering from cancer may face unique health problems that differ from their healthy counterparts. This has made parents of children with cancer already experiencing high levels of stress extremely worried about the possible consequences of cancer and the outbreak [25]. Additional psychosocial stress may reduce their QOL and increase fatigue [26]. A study conducted in the United Kingdom showed that parents with children with cancer believe that their children are at a higher risk of infection compared to their healthy peers [27]. This belief also prevents children with cancer from participating in activities involving social participation and can cause a decrease in QOL and well-being by confronting a more foster family. Dealing with both conditions (cancer and COVID-19) as two complex and deadly diseases has created a new challenge for children and their families. This experience differs completely from those of healthy peers who have encountered COVID-19 and therefore require in-depth understanding [24].

To reduce the risk of their immunocompromised children becoming exposed and infected with COVID-19, parents prefer their children to stay indoors at home and avoid participating in any outdoor activities during the pandemic $[3,28,29]$. This restriction may put children at less risk of being involved in age-appropriate occupations, and may cause lower levels of occupational performance (OP) and satisfaction with this performance [30]. OP represents the functioning of a person in his or her occupational roles and is a means of connecting an individual to these roles and sociocultural contexts [31]. Limited performance and participation restrictions in any occupation are associated with poor health-related QOL and increased behavioral disorders. For this reason, it is extremely important to detect changes in children's performance during the pandemic period in order to prevent the occurrence of bigger problems [31].

During the COVID-19 pandemic, children with cancer are included in the risky group due to both increased infection risk and increased fear of death. However, the experiences of these children and their families during the quarantine period and the difficulties they face have not yet been described sufficiently in the literature. Determining the changes in the QOL and OP level of children with cancer during the pandemic, determining the rehabilitation needs of their children together with families, can guide the development of strategies that will improve the QOL of these children and increase their occupational participation and performance. Therefore, this study aimed to determine the changes in health and cancer-related QOL, OP levels, and rehabilitation needs of children with cancer during the quarantine period.

\section{Methods}

\section{Study design}

This study was carried out to determine the changes in the QOL and OP of children with cancer during the pandemic period and the areas of support they need in this period. A mixed method was designed using both quantitative and qualitative interview methods. The framework of the study design is summarized in Fig. 1.

Our mixed method design was the concurrent transformative. In this design, quantitative and qualitative data are collected and analyzed at the same time. Although priority is given to qualitative or quantitative data types, equal importance can be given to both data types in some 


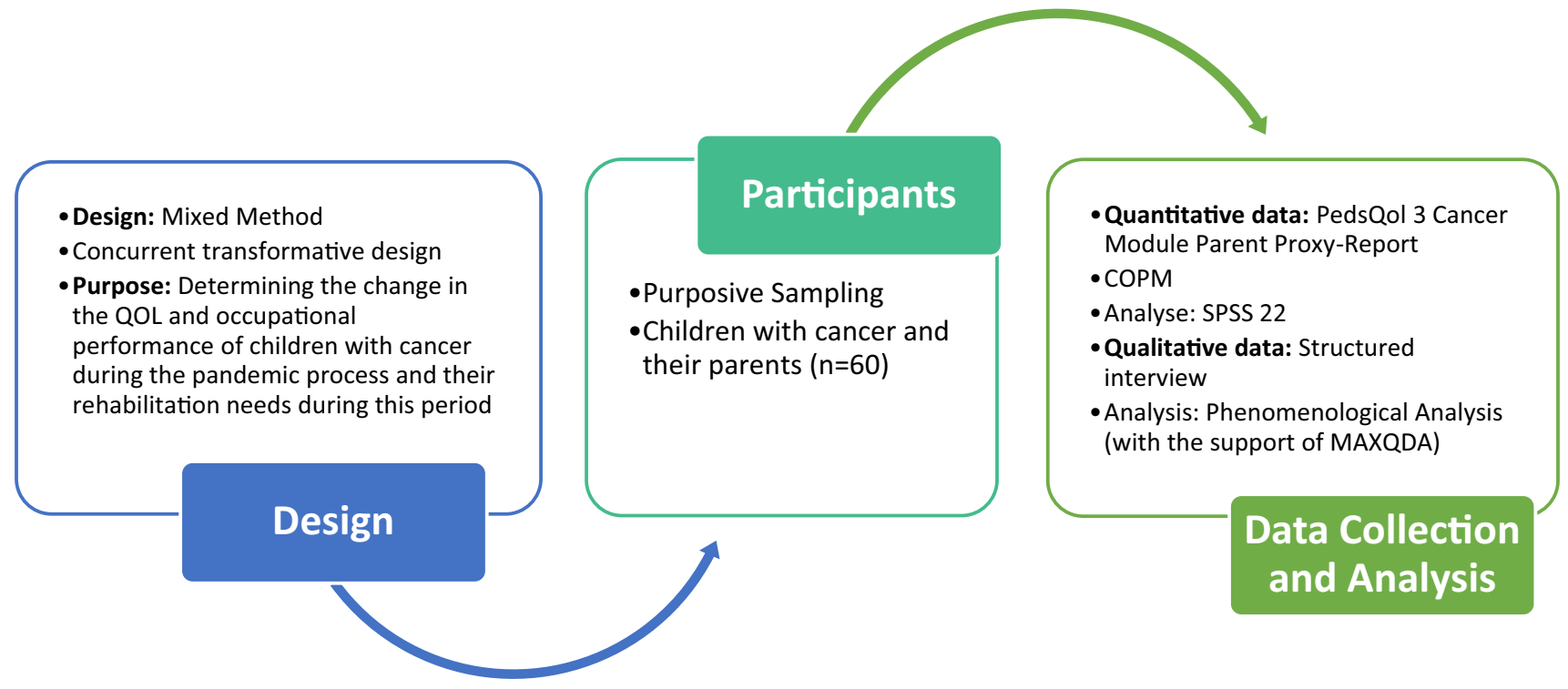

Fig. 1 Summary of the study design. $Q O L$ quality of life, $P e d s Q o l$ the pediatric quality of life inventory, COPM Canadian occupational performance measure, SPSS statistical package for the social sciences

cases [32]. In this study, equal importance was given to both data types. Data analysis is done separately, and merging usually occurs during the data interpretation phase. This design is useful to allow broad or alternative perspectives, being supportive of the research participants, and providing a better understanding of the phenomenon being studied [33].

A study invitation was prepared and sent out to families of children with cancer in the last week of March 2020; a week after it was declared a pandemic in Turkey. The study invitation, including the research content, purpose and method, was shared with cancer support groups via online channels (Facebook/Twitter). The compliance with the inclusion criteria of the participants who volunteered in the study was evaluated through the Sociodemographic Questionnaire Google Form sent via e-mail. After the online confirmations of eligible children and their families were obtained, PedsQOL-3 was applied to parents via Google Form to evaluate the changes in the QOL of children with cancer in the beginning of April 2020. COPM was applied to children with cancer to determine the OP levels and their satisfaction levels of these performances in their daily lives through online interviews (Zoom/Skype). In September 2020, families were invited to the study once again to determine the QOL and OP levels of children with cancer whereby the evaluations were repeated with the same methods, and a structured interview was held with the parents to determine the impact of the pandemic period on children with cancer and their parents alongside the rehabilitation needs of these children. The structured interview was carried out using online interview techniques (phone conservation/Zoom/Skype). The data obtained with PedsQOL-3 was recorded on Google Form, and the data obtained from the COPM and structured interview were voice recorded (phone call) or video recorded (Zoom/ Skype) according to the interview method; with the permission of children and their family.

\section{Study population}

Children with cancer were eligible if met the following inclusion criteria: (a) diagnosed with cancer, (b) aged between 6 and 12 years, (c) ongoing cancer treatment. Children were ineligible if they: (a) had relapsed or were in palliative care, (b) had mental or developmental disability (autism spectrum disorder, attention deficit hyperactivity disorder (ADHD), mental retardation, etc.).

After the invites, out of 118 families interviewed, 79 agreed to participate in the study and of these, 11 children subsequently met the exclusion criteria: finished treatment (3), had mental or developmental disability $(n=4)$ and relapsed $(n=4)$. Therefore, 68 children with cancer and their parents were included in the study.

As described in the study design, children with cancer and their parents who gave consent to participate in the online research were invited twice; in April and September 2020 for the evaluation. Eight families were excluded from the study because they did not accept the second evaluation for various reasons. The research was completed with 60 participants. 


\section{Measurements}

\section{Sociodemographic form}

The first evaluation questioned the demographic information of the children and caregivers. In addition to the information regarding their age, gender, cancer diagnosis, diagnosis period, treatment process and educational process of the children, child's family and their social environment were also asked about.

\section{Canadian occupational performance measure (COPM)}

This measure determines occupational preferences and priorities; and evaluates the perceived OP and satisfaction while performing the occupation [34]. The individuals were asked to state OP problems and concerns in three performance areas; self-care, productivity and leisure activities [35]. The importance of activities were ranked between 1 and 10 (1: not important, 10: very important), and then the top five were graded in terms of performance and satisfaction levels. Torpil et al. carried out the reliability, validity, and feasibility of the Turkish version of the COPM [36].

\section{Pediatric quality of life inventory parent proxy-report (PedsQOL-3)}

The PedsQOL 3.0 was developed by Varni in pediatric cancer patients [37, 38]. It consists of 27 items: pain and hurt (2), nausea (5), procedural anxiety (3), treatment anxiety (3), worry (3), cognitive problems (5), perceived physical appearance (3), and communication (3). Higher scores indicate better QOL [38].

Kabak et al. carried out the reliability, validity, and feasibility of the Turkish version of the PedsQL 3.0 [39]. The original form of the test, translated into Turkish, was used with the consent of its authors.

\section{Structured interview}

We applied a qualitative approach, phenomenology, to pool and analyze experiences reported by parents of children with cancer. A phenomenological approach allows the investigator to distil the essence of the experience by coding and categorizing data to identify themes [40]. The interviewer used open-ended probes to clarify incomplete or ambiguous responses.

Within the meeting, interviews were held to reveal the pandemic experiences of the parents from their perspective. Telephone calls or online channels (Zoom/Skype) were held according to the access status of the parents. Each meeting lasted about thirty minutes. During the interviews, voice recordings were taken with the permission of the families. The two main questions of the interview were:

How have you and your child been affected by the COVID-19 pandemic?

Are there any issues you would like to be supported with regarding your child during the pandemic period?

\section{Data analysis}

\section{Quantitive data}

Statistical analyses were performed using SPSS software version 22 . The variables were investigated using visual (histograms, probability plots) and analytical (Kolmogorov Simirnov/Shapiro-Wilk test) methods to determine whether they are normally distributed. Descriptive analyses were presented using the median and interquartile range (IQR) for the non-normally distributed and ordinal variables. Since the QOL, OP and satisfaction points were not normally distributed; the Wilcoxon test was used to compare change in these parameters between baseline and 6 months. A $p$ value of less than 0.05 was considered to show a statistically significant result.

\section{Qualitative data}

We handled qualitative data according to standard phenomenological analysis procedures [41] and data analysis is explained in Appendix 1.

\section{Results}

\section{Participant characteristics}

60 parents in this study compromised 37 mothers and 23 fathers. Mean parental age was 36.8 years $(\mathrm{SD}=4.6)$; with a mean age of mothers being $36.7(\mathrm{SD}=4.3)$ and fathers 36.9.2 $(\mathrm{SD}=4.8)$. The mean age of the children was 8.9 years $(\mathrm{SD}=1.5)$ and the sample was heterogeneous for the cancer type. Parent and child characteristics are summarized in Table 1. 
Table 1 Characteristics of participants $(N=60)$

\begin{tabular}{|c|c|c|c|}
\hline & & $M(\mathrm{SD})$ & Range \\
\hline Age of children (years) & & $8.9(1.5)$ & $6-12$ \\
\hline \multicolumn{4}{|l|}{ Age of parent (years) } \\
\hline Mother & & $36.7(4.3)$ & $30-47$ \\
\hline Father & & $36.9(4.8)$ & $29-51$ \\
\hline \multirow[t]{2}{*}{ Number of chemotherapy cycles } & & $8.5(3)$ & $4-20$ \\
\hline & \multicolumn{3}{|c|}{ Frequency $(\%)$} \\
\hline \multicolumn{4}{|l|}{ Gender } \\
\hline Male & $34(56.7)$ & & \\
\hline Female & $26(43.3)$ & & \\
\hline \multicolumn{4}{|l|}{ Diagnosis } \\
\hline Brain tumors & $11(18.3)$ & & \\
\hline Neuroblastoma & $14(23.3)$ & & \\
\hline Leukemia & $15(25)$ & & \\
\hline Lymphoma & $15(25)$ & & \\
\hline Bone tumors & $5(8.3)$ & & \\
\hline \multicolumn{4}{|l|}{ Time after diagnosis } \\
\hline 3 months or less & $1(1.7)$ & & \\
\hline $3-6$ months & $13(21.7)$ & & \\
\hline $6-12$ months & $27(45)$ & & \\
\hline 12 months or more & $19(31.7)$ & & \\
\hline \multicolumn{4}{|l|}{ Radiotherapy } \\
\hline Yes & $24(40)$ & & \\
\hline No & $36(60)$ & & \\
\hline \multicolumn{4}{|l|}{ Surgery } \\
\hline Yes & $29(48.3)$ & & \\
\hline No & $31(51.7)$ & & \\
\hline \multicolumn{4}{|l|}{ Relationship to child } \\
\hline Mother & $37(61.7)$ & & \\
\hline Father & $23(38.3)$ & & \\
\hline
\end{tabular}

$N$ number, $M$ mean, $S D$ standard deviation

\section{Quantitive results}

\section{Results of the QOL of children with cancer}

According to the results of the PedsQOL, the QOL of children with cancer significantly decreased during the COVID-19 pandemic period. There was no statistical change in the pain-related conditions of the children within six months of the pandemic $(p>0.05)$. Procedural anxiety and treatment anxiety of children during treatment increased in this period; QOL parameters including cognitive state, perceived physical appearance and communication skills also showed a statistically significant decrease $(p<0.05)$ (Fig. 2).

\section{Results on the occupational performance and satisfaction of children with cancer}

According to the COPM results, the children's pre-pandemic OP score was $5.5(\mathrm{SD}=1.1)$, satisfaction score was $4.8(\mathrm{SD}=1.2)$; the OP score six months after the pandemic began was $3.9(\mathrm{SD}=1.3)$, satisfaction score was $2.2(\mathrm{SD}=1.3)$. Both the $\mathrm{OP}$ and satisfaction of children with cancer decreased significantly in the 6 -month period covering the pre-pandemic and pandemic period $(p<0.01)$ (Table 2).

While the OP of the children accumulated above 5 points before the pandemic, this accumulation decreased to 4 points after 6 months. Children's satisfaction piled up at 4 points before the pandemic, but after 6 months this accumulation decreased to 1 point (Fig. 3). 


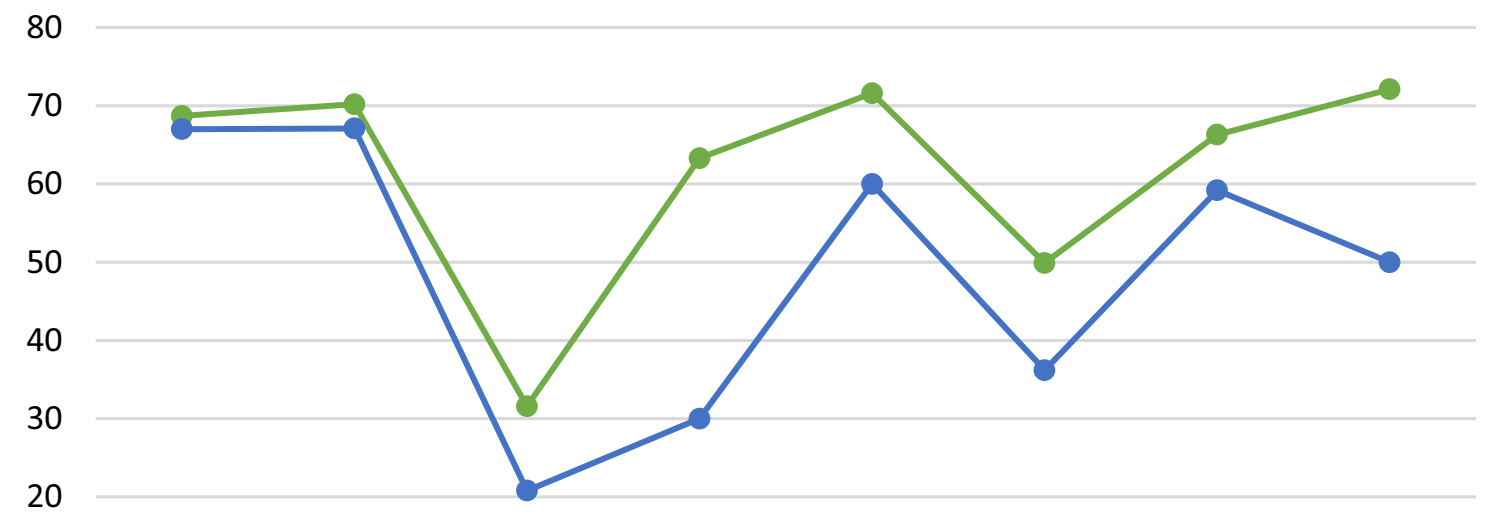

10

\begin{tabular}{|c|c|c|c|c|c|c|c|c|}
\hline & $\begin{array}{c}\text { Pain and } \\
\text { hurt }\end{array}$ & Nausea & $\begin{array}{l}\text { Procedural } \\
\text { anxiety } * *\end{array}$ & $\begin{array}{l}\text { Treatment } \\
\text { anxiety } * *\end{array}$ & Worry ** & $\begin{array}{c}\text { Cognitive } \\
\text { problems ** }\end{array}$ & $\begin{array}{c}\text { Perceived } \\
\text { physical } \\
\text { appearance } \\
* *\end{array}$ & $\begin{array}{l}\text { Communica } \\
\text { - tion } * *\end{array}$ \\
\hline — Before Covid 19 & 68.7 & 70.2 & 31.6 & 63.3 & 71.6 & 49.9 & 66.3 & 72.1 \\
\hline$\longrightarrow$ After Covid 19 & 67 & 67.1 & 20.8 & 30 & 60 & 36.2 & 59.2 & 50 \\
\hline
\end{tabular}

Fig. 2 Change in children's QOL scores before and after the pandemic period. * $p<0.05 ; * * p<0.01$

Table 2 Change in children's occupational performance and satisfaction scores before and after the set pandemic period

\begin{tabular}{|c|c|c|c|c|c|c|c|c|}
\hline & \multicolumn{3}{|c|}{ Before COVID-19 } & \multicolumn{3}{|c|}{ After 6 months } & \multicolumn{2}{|c|}{$\begin{array}{l}\text { Change after } \\
6 \text { months }\end{array}$} \\
\hline & $M(\mathrm{SD})$ & Median & Range & $M(\mathrm{SD})$ & Median & Range & $Z$ & $p$ \\
\hline$-\mathrm{OP}$ & $5.5(1.1)$ & 5 & $4-8$ & $3.9(1.2)$ & 4 & $2-7$ & -6.232 & $<0.001$ \\
\hline -OS & $3.8(1.3)$ & 4 & $1-6$ & $2.2(1.3)$ & 2 & $1-6$ & -6.518 & $<0.001$ \\
\hline -Total & $9.4(1.5)$ & 9.5 & $6-13$ & $6.1(1.7)$ & 6 & $4-11$ & -6.716 & $<0.001$ \\
\hline
\end{tabular}

$M$ mean, $S D$ standard deviation, $O P$ occupational performance, $O S$ occupational satisfaction

\section{Qualitative results}

After categorizing parents' statements, qualitative data analysis continued by clustering and organizing the categories and by identifying themes. Table 2 lists the categories we identified for both questions; the theme generated for each category and selected statements from parents' which illustrates each category and its theme. The qualitative analysis suggests that children with cancer and their parents' are negatively affected, positively affected or not affected by the pandemic process. In addition, parents' expressed their children's needs for physical and psychological support, social participation support, and time management (Table 3).

\section{Discussion}

To our knowledge, this is the first study to evaluate the impact of the COVID-19 pandemic on the QOL and OP of children with cancer. This study has shown that children with cancer who are undergoing treatment had a decrease in their QOL during the COVID-19 pandemic period, their OP and satisfaction levels in their daily routine had decreased and they needed rehabilitation in this period.

It is known from the literature that the QOL of children with cancer is low in comparison with their healthy peers $[42,43]$. This study showed the decline in the QOL of these children during the COVID-19 pandemic period. Apart from the pain and nausea, negative changes occurring in operational anxiety, treatment anxiety, worry, cognitive state, perceived physical appearance and communication skills were observed. 


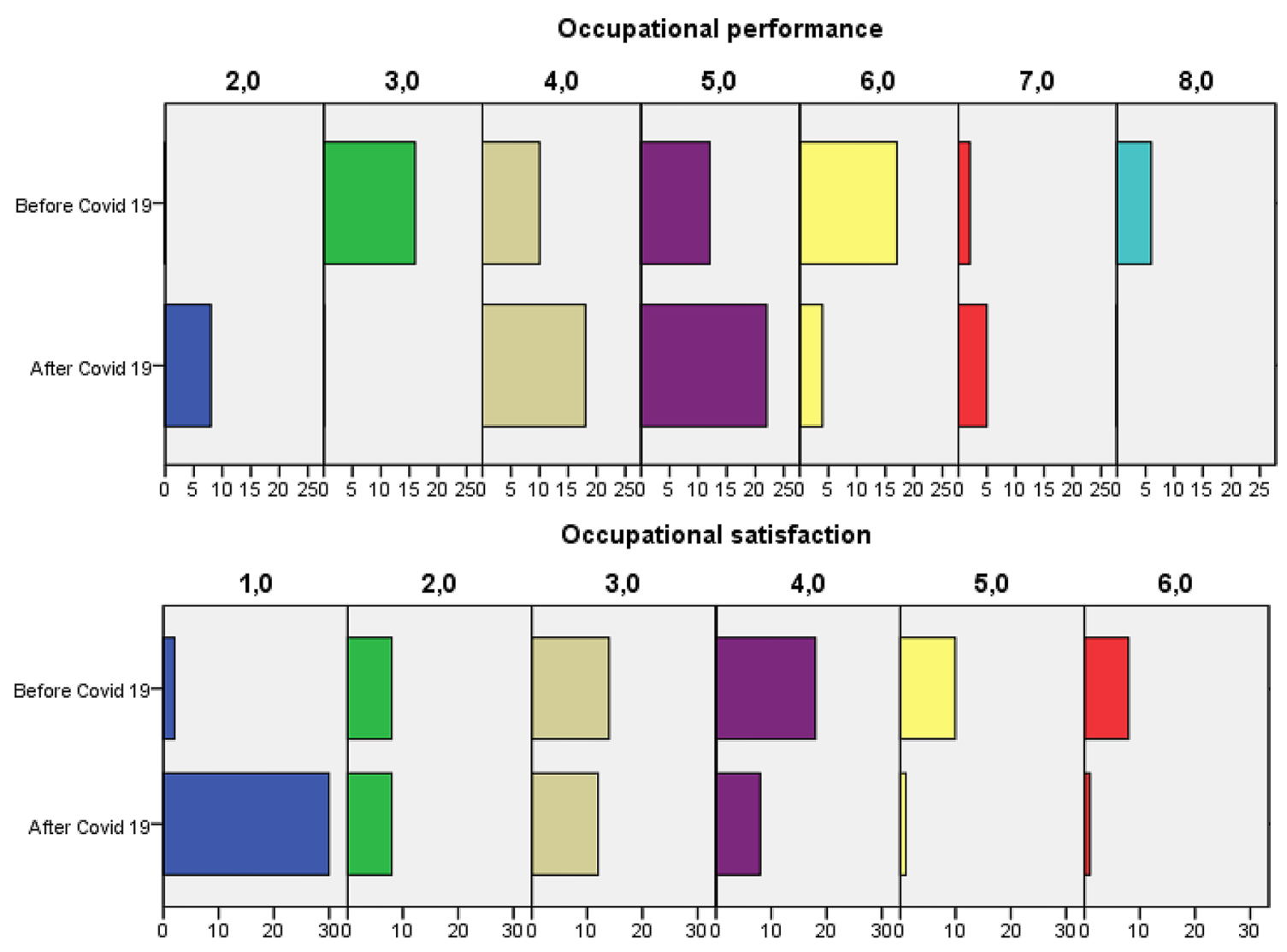

Fig. 3 The distribution of children's occupational performance and satisfaction scores

Current research indicates that clinical pediatric cancer care has been significantly disrupted by the COVID-19 outbreak, as opposed to maintaining continuity [44]. This study showed that besides treatment-related anxiety, children with cancer also had an increase in general worry levels. Pandemic prevention measures including social distancing increases the psychosocial stress of children with cancer who already have high levels of stress and anxiety [26]. Previous studies asking specifically about the stress associated with COVID-19 found that teenagers with cancer fear getting sick and experience serious complications and adolescents and young adults with cancer were at high risk for psychological distress during the period of COVID-19 [45, 46].

The new and unusual situations related to the pandemic period, increase stress and anxiety in the routine life, bring about social isolation and concerns for the future [47]. Studies state that perceived physical appearance is directly related to cognitive states and psychological states such as stress, anxiety in children [48, 49]. Perceived physical appearance is defined as the picture of people's body which they form in their mind and cognitive assessment of one's physical characteristics [49]. For this reason, the negative changes in the perceived physical appearance of children with cancer, who have both increased anxiety levels and cognitive problems during the pandemic period, is not a surprising result.

Van Gorp et al. [26] stated that there was no change in the QOL of outpatient children with cancer in the Netherlands before and after COVID-19. We think that the different results of the researches in the literature may be related to the development level of health systems of countries. Van Gorp et al. [26] stated that digital treatment methods are used in the center where the study was conducted, and the psychosocial needs of children and families with cancer continued without interruption. In our study population, parents talked about the anxiety experienced by their children when they go out and the necessity to spend more time at home. Turkey does not have an example of psychosocial interventions carried out in the digital environment for children with cancer. Lack of this support can cause a decrease in the QOL of children.

This study showed that children with cancer had a decrease in their OP and satisfaction with this performance during thepandemic period. Children with cancer experience disintegration in childhood activities such as facing problems with self-care (dressing, bathing, eating, etc.), 


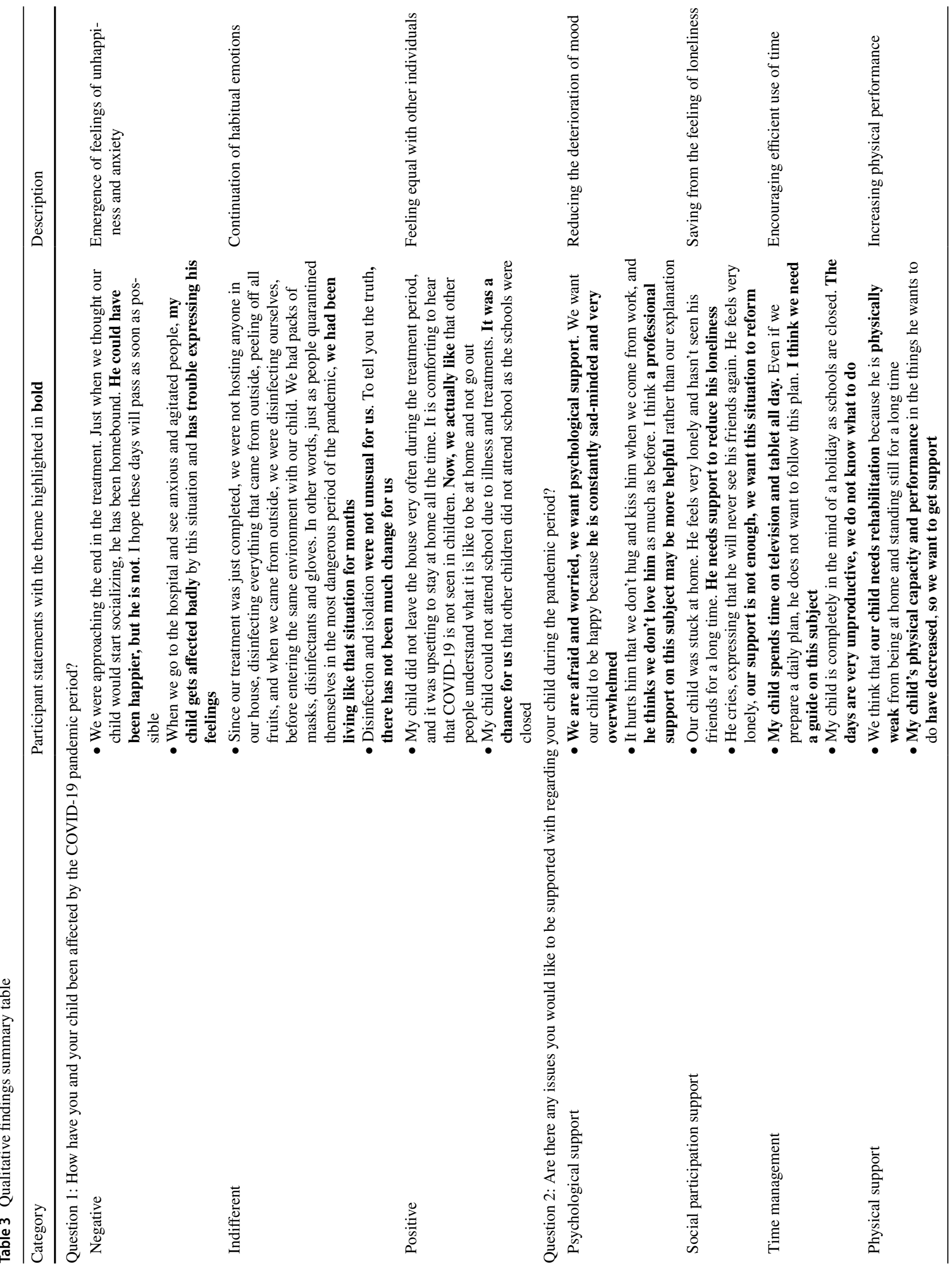


productivity (school, and routine tasks), play and leisure time (QOL and social interactions) [50]. Various studies in the literature show that children with cancer have poor OP [50-52]. During the COVID-19 pandemic period, although all individuals around the world take measures such as social distancing, wearing masks, staying at home as much as possible, higher-level measures such as "excessive social distancing" has been recommended especially for this group, as they are in the high-risk group [53]. This situation may cause a more socially restricted living in children with cancer compared to the pre-pandemic time.

Qualitative findings address determining how the children with cancer and their family are affected by the pandemic period and their support needs in this period. Because of the inductive nature of qualitative inquiry, analysis of the written reflections added specificity, depth, and unanticipated meaning to the experience.

First, similar to the pretest-posttest results, the parents described their children were negatively affected by the pandemic period. However, participant reflections extended the survey findings in two specific ways. One consistent finding was the situation regarding the need for more isolation during the pandemic period of children with cancer who were exposed to social isolation due to cancer. The children and parents who went to the hospital for treatment stated they were "more worried" due to the pandemic period and this reflected the effect on mental health, which affects the QOL. In the study of Darlington et al. [27], the parents of children with cancer define hospitals as "an unsafe environment for their children" during the pandemic period support our findings. In addition, parents' fear of being infected even when they go to the market and the fear of putting their children's lives at risk when infected force children and families to be isolated from society and pose a major threat to mental health. Besides the negative effects of the pandemic period on children's participation and mental health, parents stated this period increased the empathy of healthy individuals. Although this finding has a positive effect on mental health, it will not be enough to ignore the wide range of negative effects of the pandemic such as deterioration in the health system, changes in treatment routines, travel restrictions, social isolation, and loss of income [54].

Second, the parents stated their children's rehabilitation needs during the pandemic period regarding physical and psychological support, social participation support, and time management. Before the pandemic, children with cancer could establish peer relationships in different settings such as hospitals, foundations and associations, thus meeting their social participation needs to some extent. With the pandemic, the reduction of hospitalizations as much as possible and the interruption of social communities' activities limited the opportunities for social participation of children. Social participation is extremely important for the development of psychological, cognitive, emotional development, and communication skills in children [55]. During the pandemic period which is also seen in the QOL findings, children's cognitive weakening decreased communication skills and psychological problems such as anxiety support this situation.

The social isolation process experienced during the pandemic period and the online conduct of children's education processes brought physical inactivity. In a study conducted with the parents of healthy children in Norway, more than half of the parents stated internet use in their children has increased. In addition, the physical well-being, emotional well-being, and self-esteem scores of children were found to be lower with increased internet use [13]. Furthermore, our study also indicates that children with cancer also have increased physical inactivity and participation of children- in passive activities such as playing with tablets and watching TV shows that it has increased. The fact that education is carried out in the home environment, children have a lot of free time in this period and activities are limited with their family, therefore children tend to spend more time on the internet which bring about both physical inactivity and deterioration in time management and occupational balance [3]. Physical inactivity is associated with a wide variety of negative health consequences [56]. Regular physical activity has been shown to have protective effects by improving cardiorespiratory fitness, reducing fatigue, promoting psychological health and, most importantly, strengthening the immune system [57, 58]. Considering the effect of physical activity on health-related QOL and the immune system, it is crucial for children with cancer to participate in regular physical activities.

\section{Limitations}

Our study has several limitations. Since the study was conducted under pandemic conditions, it was carried out throughonline and telephone calls. Therefore, families with limited access to technological opportunities may not have been reached. We think that reaching families with different economic and cultural levels, after equality of opportunity is established regarding the use of information and communication technologies will increase the generalizability of the results.

In addition, collecting quantitative data through Google form has some limitations. Among these limitations are the difficulty of delivering Google forms to large populations, the possibility of participants to leave the questions halfway and leave the study, and the data loss due to internet interruptions. Since the study was completed with both quantitative and qualitative methods, the accuracy of the quantitative data collected with the Google form was supported by the qualitative data collected through live interviews. For this 
reason, Google form may have limited reaching the larger population, but it is not seen as a threat to data reliability and accuracy.

\section{Conclusion and future directions}

Our study has shown that the pandemic period leads to a decrease in the QOL of children with cancer, a decrease in their OP in routine life and in their satisfaction of this performance. In addition, it has been revealed that children with cancer need psychological support, time management support, social participation support and physical support during the pandemic period. These results may help healthcare professionals working with children with cancer to understand the psychosocial status of children with cancer in the pandemic.

A person's well-being is dependent not only on personal characteristics but also on the social environments and resources around them [59]. Therefore, social adaptation to the pandemic period can support the improvement of the QOL of children. However, under the conditions we are in, approaches that support the improvement of the QOL of children with cancer and intervention approaches based on occupation to increase their OP should be delivered to children by using remote communication methods.

It is important to include children with cancer in peer groups which support the psychosocial development and increase their social participation and communication skills under pandemic conditions. The efficient use of time by children with cancer, maintaining and improving their physical activeness by avoiding sedentary life are also important issues that should be included in remote rehabilitation programs.

Supplementary Information The online version contains supplementary material available at https://doi.org/10.1007/s11136-021-02857-7.

Funding This research received no specific grant from any funding agency in the public, commercial or not-for-profit sectors.

Data availability Data available upon request.

\section{Declarations}

Conflict of interest The authors report no actual or potential conflict of interest.

Ethical approval Ethics Committee approval was obtained for the study from Hacettepe University Non-Invasive Clinical Investigation Ethics Committee (Approval Number GO 21/45) and it was examined by the ministry of health and the studies carried out in the COVID-19 pandemic were found in accordance with the regulation (File Number: 26T14_36_47). The procedures used in this study adhere to the tenets of the Declaration of Helsinki.
Informed consent All respondents and their parents signed written informed consent forms for participation.

\section{References}

1. Harapan, H., Itoh, N., Yufika, A., Winardi, W., Keam, S., Te, H., Megawati, D., Hayati, Z., Wagner, A. L., \& Mudatsir, M. (2020). Coronavirus disease 2019 (COVID-19): A literature review. Journal of Infection and Public Health, 13(5), 667-673

2. Jebril, N. (2020). World Health Organization declared a pandemic public health menace: A systematic review of the coronavirus disease 2019 "COVID-19." International Journal of Psychosocial Rehabilitation, 24(9), 9160-9166. https://doi.org/10.37200/IJPR/ V24I9/PR290311

3. Cheung, A. T., Li, W. H. C., Ho, L. L. K., Chan, G. C. F., \& Chung, J. O. K. (2020). Health support to pediatric cancer survivors and their families during the COVID-19 pandemic. Pediatric Blood \& Cancer, 67(11), e28441. https://doi.org/10.1002/pbc. 28441

4. Alradhawi, M., Shubber, N., Sheppard, J., \& Ali, Y. (2020). Effects of the COVID-19 pandemic on mental well-being amongst individuals in society-A letter to the editor on "The socio-economic implications of the coronavirus and COVID-19 pandemic: A review." International Journal of Surgery, 78, 147-148. https:// doi.org/10.1016/j.ijsu.2020.04.070

5. Sheridan Rains, L., Johnson, S., Barnett, P., Steare, T., Needle, J. J., Carr, S., Lever Taylor, B., Bentivegna, F., Edbrooke-Childs, J., Scott, H. R., Rees, J., Shah, P., Lomani, J., Chipp, B., Barber, N., Dedat, Z., Oram, S., Morant, N., Simpson, A., \& COVID19 Mental Health Policy Research Unit Group. (2021). Early impacts of the COVID-19 pandemic on mental health care and on people with mental health conditions: framework synthesis of international experiences and responses. Social Psychiatry and Psychiatric Epidemiology, 56(1), 13-24. https://doi.org/10.1007/ s00127-020-01924-7

6. Banerjee, D. (2020). The COVID-19 outbreak: Crucial role the psychiatrists can play. Asian Journal of Psychiatry, 50, 102014. https://doi.org/10.1016/j.ajp.2020.10201

7. Duan, L., \& Zhu, G. (2020). Psychological interventions for people affected by the COVID-19 epidemic. The Lancet Psychiatry, 7(4), 300-302. https://doi.org/10.1016/S2215-0366(20)30073-0

8. Ferreira, L. N., Pereira, L. N., da Fé Brás, M., \& Ilchuk, K. (2021). Quality of life under the COVID-19 quarantine. Quality of Life Research. https://doi.org/10.1007/s11136-020-02724-x

9. Ravens-Sieberer, U., Kaman, A., Erhart, M., Devine, J., Schlack, R., \& Otto, C. (2021). Impact of the COVID-19 pandemic on quality of life and mental health in children and adolescents in Germany. European Child \& Adolescent Psychiatry. https://doi. org/10.1007/s00787-021-01726-5

10. Arnett, J. J. (2015). The Oxford handbook of emerging adulthood. Oxford University Press.

11. Orben, A., Tomova, L., \& Blakemore, S. J. (2020). The effects of social deprivation on adolescent development and mental health. The Lancet Child \& Adolescent Health, 4(8), 634-640. https://doi. org/10.1016/S2352-4642(20)30186-3

12. Copeland, W. E., McGinnis, E., Bai, Y., Adams, Z., Nardone, H., Devadanam, V., Rettew, J., \& Hudziak, J. J. (2021). Impact of COVID-19 pandemic on college student mental health and wellness. Journal of the American Academy of Child and Adolescent Psychiatry, 60(1), 134-141.e2. https://doi.org/10.1016/j.jaac.2020. 08.466

13. Riiser, K., Helseth, S., Haraldstad, K., Torbjørnsen, A., \& Richardsen, K. R. (2020). Adolescents' health literacy, health 
protective measures, and health-related quality of life during the COVID-19 pandemic. PLoS ONE, 15(8), e0238161. https://doi. org/10.1371/journal.pone.0238161

14. Dalton, L., Rapa, E., \& Stein, A. (2020). Protecting the psychological health of children through effective communication about COVID-19. The Lancet Child \& Adolescent Health, 4(5), 346347. https://doi.org/10.1016/S2352-4642(20)30097-3

15. Duan, L., Shao, X., Wang, Y., Huang, Y., Miao, J., Yang, X., \& Zhu, G. (2020). An investigation of mental health status of children and adolescents in china during the outbreak of COVID-19. Journal of Affective Disorders, 275, 112-118. https://doi.org/10. 1016/j.jad.2020.06.029

16. Jiao, W. Y., Wang, L. N., Liu, J., Fang, S. F., Jiao, F. Y., PettoelloMantovani, M., \& Somekh, E. (2020). Behavioral and emotional disorders in children during the COVID-19 epidemic. The Journal of Pediatrics, 221, 264-266.e1. https://doi.org/10.1016/j.jpeds. 2020.03.013

17. Xie, X., Xue, Q., Zhou, Y., Zhu, K., Liu, Q., Zhang, J., \& Song, R. (2020). Mental health status among children in home confinement during the coronavirus disease 2019 outbreak in Hubei Province China. JAMA Pediatrics, 174(9), 898-900. https://doi.org/10. 1001/jamapediatrics.2020.1619

18. Yeasmin, S., Banik, R., Hossain, S., Hossain, M. N., Mahumud, R., Salma, N., \& Hossain, M. M. (2020). Impact of COVID-19 pandemic on the mental health of children in Bangladesh: A crosssectional study. Children and Youth Services Review, 117, 105277. https://doi.org/10.1016/j.childyouth.2020.105277

19. Jibb, L. A., Croal, L., Wang, J., Yuan, C., Foster, J., Cheung, V., Gladstone, B. M., \& Stinson, J. N. (2018). Children's experiences of cancer care: A systematic review and thematic synthesis of qualitative studies. Oncology Nursing Forum, 45(4), 527-544. https://doi.org/10.1188/18.ONF.527-544

20. Loeffen, E., Knops, R., Boerhof, J., Feijen, E., Merks, J., Reedijk, A., Lieverst, J. A., Pieters, R., Boezen, H. M., Kremer, L., \& Tissing, W. (2019). Treatment-related mortality in children with cancer: Prevalence and risk factors. European Journal of Cancer, 121, 113-122. https://doi.org/10.1016/j.ejca.2019.08.008

21. Tian, Y., Qiu, X., Wang, C., Zhao, J., Jiang, X., Niu, W., Huang, J., \& Zhang, F. (2021). Cancer associates with risk and severe events of COVID-19: A systematic review and meta-analysis. International Journal of Cancer, 148(2), 363-374. https://doi. org/10.1002/ijc.33213

22. Ciążyńska, M., Pabianek, M., Szczepaniak, K., Ułańska, M., Skibińska, M., Owczarek, W., Narbutt, J., \& Lesiak, A. (2020). Quality of life of cancer patients during coronavirus disease (COVID-19) pandemic. Psycho-Oncology, 29(9), 1377-1379. https://doi.org/10.1002/pon.5434

23. Younger, E., Smrke, A., Lidington, E., Farag, S., Ingley, K., Chopra, N., Maleddu, A., Augustin, Y., Merry, E., Wilson, R., Benson, C., Miah, A., Zaidi, S., McTiernan, A., Strauss, S. J., Dileo, P., Gennatas, S., Husson, O., \& Jones, R. L. (2020). Healthrelated quality of life and experiences of sarcoma patients during the COVID-19 pandemic. Cancers, 12(8), 2288. https://doi.org/ $10.3390 /$ cancers 12082288

24. Mirlashari, J., Ebrahimpour, F., \& Salisu, W. J. (2020). War on two fronts: Experience of children with cancer and their family during COVID-19 pandemic in Iran. Journal of Pediatric Nursing, 57, 25-31. https://doi.org/10.1016/j.pedn.2020.10.024

25. Kotecha, R. S. (2020). Challenges posed by COVID-19 to children with cancer. The Lancet Oncology, 21(5), e235. https://doi.org/10. 1016/S1470-2045(20)30205-9

26. van Gorp, M., Maurice-Stam, H., Teunissen, L. C., van de der Peppel-van Meer, W., Huussen, M., Schouten-van Meeteren, A., \& Grootenhuis, M. A. (2021). No increase in psychosocial stress of Dutch children with cancer and their caregivers during the first months of the COVID-19 pandemic. Pediatric Blood \& Cancer, 68(2), e28827. https://doi.org/10.1002/pbc.28827

27. Darlington, A. E., Morgan, J. E., Wagland, R., Sodergren, S. C., Culliford, D., Gamble, A., \& Phillips, B. (2021). COVID-19 and children with cancer: Parents' experiences, anxieties and support needs. Pediatric Blood \& Cancer, 68(2), e28790. https://doi.org/ 10.1002/pbc. 28790

28. Damani, A., Ghoshal, A., Rao, K., Singhai, P., Rayala, S., Rao, S., Ganpathy, K. V., Krishnadasan, N., Verginiaz, L., Vallath, N., Palat, G., Venkateshwaran, C., Jenifer, J. S., Matthews, L., Macaden, S., Muckaden, M. A., Simha, S., Salins, N., Johnson, J., ... Bhatnagar, S. (2020). Palliative care in coronavirus disease 2019 pandemic: Position statement of the Indian association of palliative CARE. Indian Journal of Palliative Care, 26(Suppl 1), S3-S7. https://doi.org/10.4103/IJPC.IJPC_207_20

29. Zhou, X., Cai, S., \& Guo, Q. (2020). Responses of pediatric palliative care to the COVID-19 pandemic in China. Pediatric Research. https://doi.org/10.1038/s41390-020-01137-3

30. Dehghan, L., Dalvand, H., Hadian Rasanani, M. R., \& Nakhostin Ansari, N. (2020). Occupational performance outcome for survivors of childhood cancer: Feasibility of the Canadian occupational performance measure. Occupational Therapy in Health Care. https://doi.org/10.1080/07380577.2020.1773011

31. Mulligan, S. (2017). Defining and measuring the occupational performance of children. Journal of Occupational Therapy, Schools, \& Early Intervention, 10(2), 107-120. https://doi.org/10.1080/ 19411243.2017.1292863

32. Creswell, J. W., Fetters, M. D., \& Ivankova, N. V. (2004). Designing a mixed methods study in primary care. The Annals of Family Medicine, 2(1), 7-12. https://doi.org/10.1370/afm.104

33. Creswell, J. W., \& Creswell, J. D. (2005). Mixed methods research: Developments, debates, and dilemmas. Research in organizations: Foundations and methods of inquiry. (pp. 315326). Berrett-Koehler Publishers.

34. Law, M., Baptiste, S., McColl, M., Opzoomer, A., Polatajko, H., \& Pollock, N. (1990). The Canadian occupational performance measure: An outcome measure for occupational therapy. Canadian Journal of Occupational Therapy, 57(2), 82-87. https://doi. org/10.1177/000841749005700207

35. Enemark Larsen, A., Rasmussen, B., \& Christensen, J. R. (2018). Enhancing a client-centred practice with the Canadian occupational performance measure. Occupational Therapy International, 2018, 5956301. https://doi.org/10.1155/2018/5956301

36. Torpil, B. (2017). Multipl Skleroz'lu bireylerde Kanada Aktivite Performans Ölçümü'nün Türkçe kültürel adaptasyonu, geçerlilik ve güvenilirliği. Retrieved October 23, 2020, from http://www. openaccess.hacettepe.edu.tr:8080/xmlui/handle/11655/3475? show $=$ full

37. Chen, X., Origasa, H., Ichida, F., Kamibeppu, K., \& Varni, J. W. (2007). Reliability and validity of the pediatric quality of life inventory (PedsQL) short form 15 generic core scales in Japan. Quality of Life Research, 16(7), 1239-1249. https://doi.org/10. 1007/s11136-007-9230-4

38. Varni, J. W., Burwinkle, T. M., Katz, E. R., Meeske, K., \& Dickinson, P. (2002). The PedsQL in pediatric cancer: reliability and validity of the pediatric quality of life inventory generic core scales, multidimensional fatigue scale, and cancer module. Cancer, 94(7), 2090-2106. https://doi.org/10.1002/cncr.10428

39. Yıldız Kabak, V., Yakut, Y., Çetin, M., \& Düger, T. (2016). Reliability and validity of the Turkish version of the PedsQL 3.0 cancer module for 2- to 7-year-old and the PedsQL 4.0 generic core scales for 5- to 7-year-old: The Hacettepe University experience. Çocuklar için Yaşam Kalitesi Ölçeği Kanser Modülü Türkçe Versiyonunun 2-7 Yaşları Arasındaki Çocuklarda ve Genel Skalası'nın 5-7 Yaşları Arasındaki Çocuklarda Geçerlik ve Güvenilirliği: Hacettepe Üniversitesi Deneyimi. Turkish Journal 
of Haematology, 33(3), 236-243. https://doi.org/10.4274/tjh.2015. 0242

40. Moustakas, C. (1994). Phenomenological research methods. Sage Publications. https://doi.org/10.4135/9781412995658

41. Polkinghorne, D. E. (1989). Phenomenological research methods. In R. S. Valle \& S. Halling (Eds.), Existential-phenomenological perspectives in psychology. (pp. 41-60). Springer.

42. Shankar, S., Robison, L., Jenney, M. E., Rockwood, T. H., Wu, E., Feusner, J., Friedman, D., Kane, R. L., \& Bhatia, S. (2005). Health-related quality of life in young survivors of childhood cancer using the minneapolis-manchester quality of life-youth form. Pediatrics, 115(2), 435-442. https://doi.org/10.1542/peds. 2004-0649

43. Speechley, K. N., Barrera, M., Shaw, A. K., Morrison, H. I., \& Maunsell, E. (2006). Health-related quality of life among child and adolescent survivors of childhood cancer. Journal of Clinical Oncology, 24(16), 2536-2543. https://doi.org/10.1200/JCO.2005. 03.9628

44. Vasquez, L., Sampor, C., Villanueva, G., Maradiegue, E., GarciaLombardi, M., Gomez-García, W., Moreno, F., Diaz, R., Cappellano, A. M., Portilla, C. A., Salas, B., Nava, E., Brizuela, S., Jimenez, S., Espinoza, X., Gassant, P. Y., Quintero, K., FuentesAlabi, S., Velasquez, T., ... Chantada, G. (2020). Early impact of the COVID-19 pandemic on paediatric cancer care in Latin America. The Lancet Oncology, 21(6), 753-755. https://doi.org/ 10.1016/S1470-2045(20)30280-1

45. Casanova, M., Pagani Bagliacca, E., Silva, M., Patriarca, C., Veneroni, L., Clerici, C. A., Spreafico, F., Luksch, R., Terenziani, M., Meazza, C., Podda, M., Biassoni, V., Schiavello, E., Chiaravalli, S., Puma, N., Bergamaschi, L., Gattuso, G., Sironi, G., Massimino, M., \& Ferrari, A. (2020). How young patients with cancer perceive the COVID-19 (coronavirus) epidemic in Milan, Italy: Is there room for other fears? Pediatric Blood \& Cancer, 67(7), e28318. https://doi.org/10.1002/pbc.28318

46. Košir, U., Loades, M., Wild, J., Wiedemann, M., Krajnc, A., Roškar, S., \& Bowes, L. (2020). The impact of COVID-19 on the cancer care of adolescents and young adults and their well-being: Results from an online survey conducted in the early stages of the pandemic. Cancer, 126(19), 4414-4422. https://doi.org/10.1002/ cncr.33098

47. de Figueiredo, C. S., Sandre, P. C., Portugal, L., Mázala-deOliveira, T., da Silva Chagas, L., Raony, I., Ferreira, E. S., Giestal-de-Araujo, E., Dos Santos, A. A., \& Bomfim, P. O. (2021). COVID-19 pandemic impact on children and adolescents' mental health: Biological, environmental, and social factors. Progress in Neuro-psychopharmacology \& Biological Psychiatry, 106, 110171. https://doi.org/10.1016/j.pnpbp.2020.110171

48. Larouche, S. S., \& Chin-Peuckert, L. (2006). Changes in body image experienced by adolescents with cancer. Journal of Pediatric Oncology Nursing, 23(4), 200-209. https://doi.org/10.1177/ 1043454206289756
49. Varni, J. W., Katz, E. R., Colegrove, R., Jr., \& Dolgin, M. (1995). Perceived physical appearance and adjustment of children with newly diagnosed cancer: A path analytic model. Journal of behavioral medicine, 18(3), 261-278. https://doi.org/10.1007/BF018 57873

50. Gharebaghy, S., Sadat Mirbagheri, S., \& Khazaeli, K. (2018). Occupational performance in children aged 6 to 13 years with cancer. Function and Disability Journal, 1(1), 49-57. https://doi. org/10.30699/fdisj.01.1.49

51. Alizadeh Zarei, M., Mohammadi, A., Mehraban, A. H., Ansari Damavandi, S., \& Amini, M. (2017). Participation in daily life activities among children with cancer. Middle East Journal of Cancer, 8(4), 213-222

52. Önal, G., \& Huri, M. (2020). Relationships between executive functions and occupational performance of children with medulloblastoma. British Journal of Occupational Therapy. https://doi. org/10.1177/0308022620939859

53. Nerli, R. B., Sanikop, A. C., Sharma, M., \& Ghagane, S. C. (2020). COVID-19 pandemic: A challenge to a child with cancer. Pediatric Blood \& Cancer, 67(9), e28512. https://doi.org/10.1002/ pbc. 28512

54. Slone, J. S., Ozuah, N., \& Wasswa, P. (2020). Caring for children with cancer in Africa during the COVID-19 crisis: Implications and opportunities. Pediatric Hematology and Oncology, 37(7), 549-553. https://doi.org/10.1080/08880018.2020.1772913

55. Pahl, K., \& Barrett, P. (2007). The development of social-emotional competence in preschool-aged children: An introduction to the fun FRIENDS program. Australian Journal of Guidance and Counselling, 17(1), 81-90. https://doi.org/10.1375/ajgc.17.1.81

56. Herbert, C., Meixner, F., Wiebking, C., \& Gilg, V. (2020). Regular physical activity, short-term exercise, mental health, and wellbeing among University students: The results of an online and a laboratory study. Frontiers in Psychology, 11, 509. https://doi.org/ 10.3389/fpsyg.2020.00509

57. Nieman, D. C., \& Wentz, L. M. (2019). The compelling link between physical activity and the body's defense system. Journal of Sport and Health Science, 8(3), 201-217. https://doi.org/ 10.1016/j.jshs.2018.09.009

58. Dwyer, M. J., Pasini, M., De Dominicis, S., \& Righi, E. (2020). Physical activity: Benefits and challenges during the COVID-19 pandemic. Scandinavian Journal of Medicine \& Science in Sports, 30(7), 1291-1294. https://doi.org/10.1111/sms.13710

59. Robinson, K. E., Gerhardt, C. A., Vannatta, K., \& Noll, R. B. (2007). Parent and family factors associated with child adjustment to pediatric cancer. Journal of Pediatric Psychology, 32(4), 400-410. https://doi.org/10.1093/jpepsy/js1038

Publisher's Note Springer Nature remains neutral with regard to jurisdictional claims in published maps and institutional affiliations. 